OPEN ACCESS

Edited by:

Akiyoshi Takami,

Aichi Medical University, Japan

Reviewed by:

Marco Falasca,

Curtin University, Australia

Karen Maegley,

Pfizer (United States), United States

${ }^{*}$ Correspondence:

Yonghan $\mathrm{He}$

heyonghan@mail.kiz.ac.cn

Specialty section:

This article was submitted to Pharmacology of Anti-Cancer Drugs,

a section of the journal

Frontiers in Oncology

Received: 04 September 2018 Accepted: 29 November 2018

Published: 11 December 2018

Citation:

He Y, Li W, Hu G, Sun H and Kong Q (2018) Bioactivities of EF24, a Novel

Curcumin Analog: A Review.

Front. Oncol. 8:614.

doi: 10.3389/fonc. 2018.00614

\section{Bioactivities of EF24, a Novel Curcumin Analog: A Review}

\author{
Yonghan $\mathrm{He}^{1 *}$, Wen $\mathrm{Li}^{2}$, Guangrong $\mathrm{Hu}^{3}$, Hui Sun ${ }^{3}$ and Qingpeng Kong ${ }^{1}$ \\ ${ }^{1}$ State Key Laboratory of Genetic Resources and Evolution, Kunming Institute of Zoology, The Chinese Academy of \\ Sciences, Kunming, China, ${ }^{2}$ Department of Endocrinology, The Third People's Hospital of Yunnan Province, Kunming, China, \\ ${ }^{3}$ Department of Emergency, The Second Affiliated Hospital of Harbin Medical University, Harbin, China
}

Curcumin is an attractive agent due to its multiple bioactivities. However, the low oral bioavailability and efficacy profile hinders its clinical application. To improve the bioavailability, many analogs of curcumin have been developed, among which EF24 is an excellent representative. EF24 has enhanced bioavailability over curcumin and shows more potent bioactivity, including anti-cancer, anti-inflammatory, and anti-bacterial. EF24 inhibits tumor growth by inducing cell cycle arrest and apoptosis, mainly through its inhibitory effect on the nuclear factor kappa B (NF-кB) pathway and by regulating key genes through microRNA (miRNA) or the proteosomal pathway. Based on the current structure, more potent EF24 analogs have been designed and synthesized. However, some roles of EF24 remain unclear, such as whether it induces or inhibits reactive oxygen species (ROS) production and whether it stimulates or inhibits the mitogen activated kinase-like protein (MAPK) pathway. This review summarizes the known biological and pharmacological activities and mechanisms of action of EF24.

Keywords: curcumin, EF24, cancer, bio-activity, inflammation, mechanism

\section{INTRODUCTION}

Many natural products have been identified for various medicinal purposes (1-3). Curcumin, a hydrophobic polyphenol derived from the rhizome of the herb Curcuma longa is a well-defined example. It has demonstrated wide-spectrum biological and pharmacological activities, such as antioxidant (4, 5), anti-inflammatory (6) antimicrobial (7-10), and anti-cancer (11) activities. Potential problems hindering the clinical use of curcumin are its low potency and poor absorption characteristics (12). The bioactivities and applications of curcumin have been well summarized elsewhere (13-17). Regardless, curcumin remains an ideal lead compound for the design of more effective analogs.

A promising curcumin analog, EF24, displays multiple potent bioactivities and increased bioavailability compared to curcumin. The chemical structures of curcumin and EF24 are shown in Figure 1. EF24 was first designed and synthesized by Adams et al. (18). The authors reported that EF24 induced cell cycle arrest and apoptosis via a redox-dependent mechanism in cancer cells (19). Later, EF24 was shown to have promising bioactivities, especially its anti-cancer activity in various solid tumors (18) and leukemia (20). Compared to the classical chemotherapy drug cisplatin, EF24 is more efficacious and less toxic (18). EF24 exerts its anti-cancer activity by inhibiting cancer cell proliferation or causing apoptosis via multiple pathways, such as inhibiting NF- $\mathrm{B}$ (21), inhibiting HIF- $1 \alpha$ activity (22), and regulating reactive oxygen species (ROS). In addition, EF24 shows promising anti-inflammatory (23-25) and anti-microbial activities (26). To improve the potency and bioavailability, new analogs were developed based on the structure of EF24. Here 


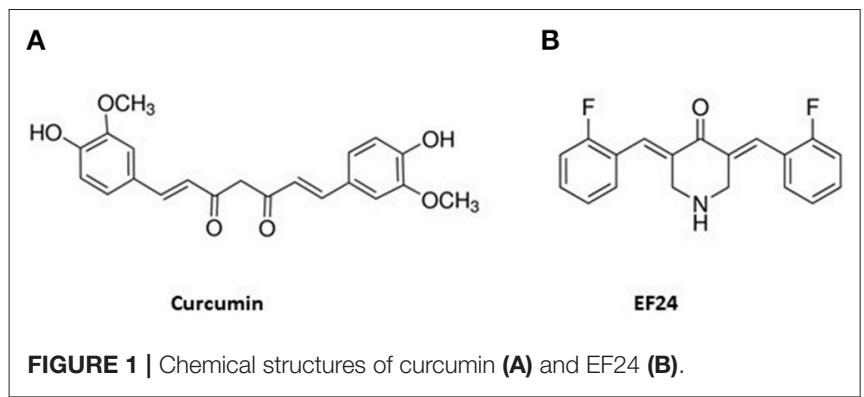

we will focus on summarizing in detail the known bioactivities and mechanisms of action of EF24 and briefly touch on the new derivatives in this review.

\section{BIOLOGICAL ACTIVITIES AND MECHANISMS OF ACTION OF EF24}

\section{Anti-cancer Activities}

In 2004, Adams et al. synthesized and screened a series of curcumin analogs, among which EF24 demonstrated a high degree of cytotoxicity to cancer cells, showing higher potency than the commonly used chemotherapeutic drug cisplatin in inhibiting tumor cell growth (18). Additionally, EF24 was found to be the most potent anti-angiogenic compound among the analogs (almost as potent as the anti-angiogenic drug TNP470) (18). In vivo studies showed that EF24 can effectively inhibit breast tumor growth with little toxicity in a mouse xenograft model (18), demonstrating the promise of EF24 as a chemotherapeutic agent for the first time. However, this study only revealed a preliminary and superficial knowledge of the mechanism for its anti-cancer effect (RNA/DNA antimetabolite) through a COMPARE analysis (18). In the next year, the authors reported that EF24 induced cell cycle arrest and apoptosis via a redox-dependent mechanism in human breast and prostate cancer cell lines (19). Evidence mainly came from the casepase-3 activation, phosphatidylserine externalization, depolarization of mitochondrial membrane potential, induction of ROS, and the inhibition of glutathione (GSH) (19).

Later, EF24 was found to have wide-spectrum anti-cancer activity. It is able to inhibit the proliferation of human cisplatinresistant ovarian cancer cells via G2/M phase cell cycle arrest and increased G2/M checkpoint proteins (p53, p21) (27). In addition, EF24 can cause apoptosis in cisplatin-resistant cells by activating phosphorylated PTEN, which subsequently inhibited Akt and MDM2, enhanced p53 levels and finally induced cell cycle arrest and apoptosis (27). Another study on ovarian carcinoma showed that EF24 time- and dose-dependently suppressed the growth and synergized with cisplatin to induce apoptosis (28). In 2008, Subramaniam et al. reported that individual use of EF24 induced caspase-mediated apoptosis and inhibited the growth of colon cancer tumor xenografts (29). Combination of EF24 with other chemotherapy drugs also showed an impressive role in suppressing colon cancer growth (30). Accumulating evidence suggests EF24 to be active in cell and/or tumor models of numerous cancer types. For example, in in-vitro experiments, it is effective in inhibiting osteogenic sarcoma cells (31), malignant pleural mesothelioma cells (32), progressive medullary thyroid cancer cells (33), human pancreatic cancer cells (34) and leukemia/lymphoma cells $(20,35)$. Whether used alone or in combination with other agents, EF24 displays great potential as an anti-cancer therapeutic.

\section{Anti-cancer Mechanisms of EF24 Inhibition of NF-kB Signaling}

Most studies suggest that EF24 impairs cell growth by inducing cell cycle arrest followed by induction of apoptosis, which is accompanied by caspase- 3 activation. However, the cell signaling pathway mediating the EF24 effect was not elucidated until 2008 when Kasinski et al. first revealed that EF24 induced cell apoptosis via suppressing NF- $\mathrm{B}$ signaling pathway through direct action on IkB kinase (IKK) (21). NF- $\kappa$ B regulates a wide variety of genes involved in cell proliferation, differentiation, cell cycle control (36), oncogenic activation (37) and metastasis (38). EF24 can inhibit the catalytic activity of IKK protein complex, which blocks $\mathrm{I} \kappa \mathrm{B}$ phosphorylation and subsequent degradation, and finally prevents the nuclear translocation of p65 subunit of NF-кB. The study provides a molecular explanation for the superior activity of EF24 over curcumin (with a potency about 10 times higher than that of curcumin). Other groups further verified the involvement of EF24 in inhibiting NF- $\mathrm{B}$ signaling pathway in cancer (39-42). EF24 robustly conferred radiationinduced cell death mainly by inhibiting radiation-induced NF- $\kappa B$ signaling in breast cancer (43). In the same year, the same group found that EF24 can suppress the radiation-induced NF-кB-DNA binding activity/promoter activation in genetically varied human neuroblastoma (44). Inhibition of the NF- $\mathrm{B}$ signaling extends the therapeutic application of EF24 to other NF-кB-dependent diseases, such as inflammatory diseases (described below).

\section{Regulation of Fanconi Anemia (FA) and MAPK Pathways}

By targeting IKK in the NF-кB pathway, EF24 was also able to inhibit the Fanconi anemia (FA) pathway, a multigene DNA damage response network implicated in the repair of DNA lesions. In HeLa cells, nanomolar concentrations of EF24 inhibited hydroxyurea (HU)-induced Fanconi anemia D2 ubiquitination (FANCD2-Ub) and foci in a cell-cycle independent manner (45). Beside the FA pathway, several other signaling pathways interplay with $\mathrm{NF}-\kappa \mathrm{B}$, one of which is the mitogen-activated protein kinase (MAPK) pathway $(46,47)$. Given the substantial role of EF24 in inhibiting NF- $\kappa$ B, scientists started to notice its role in regulating MAPK pathway. Thomas et al. reported that EF24 drastically induced the upregulation of three major MAPK pathways mediated by ERK, JNK, and p38 (48). On the contrary, Lin et al. reported that EF24 exerts its anti-tumor activity in oral squamous cell carcinoma via deactivation of the MAPK/ERK signaling pathway (49). Therefore, the effect of EF24 on the MAPK pathway is still under debate and needs to be verified in more cancer types in the future. 


\section{Regulation of HIF-1 $\alpha$ Expression}

Another important role of EF24 is to regulate HIF- $1 \alpha$ expression which is closely associated with the outcome of chemotherapy in cancer treatment. For example, Liang et al. reported that sorafenib therapy could induce drug resistance in the treatment of hepatocellular carcinoma, in which HIF- $1 \alpha$ plays an important role (50). Anti-angiogenic effects of sustained sorafenib therapy caused intratumor hypoxia, which induced HIF- $1 \alpha$ and protected cancer cells from sorafenib treatment. EF24 can inhibit HIF-1 $\alpha$ by sequestering it in cytoplasm and can promote its degradation by upregulating Von Hippel-Lindau tumor suppressor (VHL). Combination of EF24 and sorafenib showed synergistic effects against metastasis both in vivo and in vitro (50), providing compelling evidence for the potential of clinical application of EF24. Similar to EF24, the parent compound curcumin can also regulate HIF- $1 \alpha$ expression (51), albeit through distinct mechanisms. Curcumin inhibited HIF- $1 \alpha$ gene transcription, while EF24 exerted the activity by inhibiting HIF-1 $\alpha$ posttranscriptionally (22).

\section{Regulation of ROS Production}

The oncogenic factor HIF- $1 \alpha$ is implicated in regulating aerobic glycolysis and the expression of Glut1 (52). Since, EF24 was able to inhibit HIF- $1 \alpha$ activity, it likely affects glucose metabolism, thereby regulating cancer cell survival. Actually, unlike normal cells which produce energy through mitochondrial oxidative phosphorylation, most cancer cells produce their energy predominantly through a high rate of glycolysis followed by lactic acid fermentation, even in the presence of abundant oxygen, which is termed the Warburg effect (53). Although less efficient than oxidative phosphorylation in terms of ATP production, aerobic glycolysis generates additional metabolites that may help cancer cells to proliferate and growth. EF24 has been reported to block glucose uptake and the rate of glycolysis, and thereby inhibits cell migration and invasion in ovarian cancer cells (54). Another notable anti-tumor mechanism of EF24 is regulation of ROS production. Elevated oxidative status has been found in many types of cancer cells, which contributes to carcinogenesis (55-57). In 2014, Roy et al. reported that EF24 could protect protein disulfide isomerase (PDI), an important endoplasmic reticulum-resident oxidoreductase chaperone, from ROS-induced damage (58). In human ovarian cancer cells, EF24 suppressed ROS generation and activated antioxidant response element (ARE)-dependent gene transcription (28). Similarly, EF24 suppressed the level of superoxide in combination with SN38 in cancerous tissue (30). On the contrary, some other studies found that EF24 induces ROS production. The authors who first designed and synthesized EF24 observed that it was able to induce ROS production in MDA-MB-231 human breast cancer cells and DU-145 human prostate cancer cells (19). Similarly, EF24 was reported to induce ROS production in gastric cancer cells (59), and show synergistic anti-tumor activity with rapamycin (60) or Akt inhibitor (61). The same group reported a similar effect of EF24 on inducing ROS in human colon cancer lines (HCT-116 and SW-620 cells), but moderate effects in HT-29 cells (62). Therefore, it seems that the role of EF24 in ROS induction may be cell type-dependent, and more evidence is needed to clarify these contradictory results. Interestingly, Skoupa et al. recently concluded that apoptosis induced by the EF-24 is not mediated by oxidative stress-related in human leukemia cells (20). A redox-dependent-mediated mechanism only marginally contributes to the EF24-induced apoptosis in K562 cells. Therefore, the effects of EF24 on ROS and ROSmediated apoptosis in cancer cells remains to be confirmed in the further studies.

\section{Regulation of miRNA and miRNA Target Genes}

EF24 was also found to target microRNAs to regulate the tumor progress. MicroRNAs (miRNAs) are short non-coding RNAs that post-transcriptionally regulate gene expression. Dysregulation of miRNA expression in cancer has been well-established (63). Yang et al. reported that EF24 was able to downregulate miR21 and thereby enhance the expression of its target genes PTEN and PDCD4, which inhibit tumor growth and metastasis (64). Another group reported that EF24 suppressed melanoma metastasis by upregulating miR-33b and concomitantly reducing HMGA2 expression (65). The role of EF24 in regulating miRNAs provides a novel mechanism for its anti-cancer function.

\section{Comparison of EF24 to Curcumin in Anti-cancer Activity and Bioavailability}

Since the development of EF24, scientists have compared its activity with its parent compound curcumin. Most of the studies were focused on the anti-cancer activity. Adams et al. synthesized a series of curcumin analogs including EF24, and submitted them to the NCI anti-cancer cell line screen. The results showed that EF24 was effective against all of the cell lines. The mean panel $\mathrm{GI}_{50}$ (concentration at which the drug inhibits tumor cell growth by $50 \%$ ) was 10 -fold better than curcumin and cisplatin (18). The authors also submitted the analogs to an in vitro anti-angiogenesis screen and revealed that EF24 was more active than curcumin in the assay. Their in vivo experiment suggested that EF24 was well tolerated by mice and much safer than the chemotherapy drug cisplatin (18). Later, Subramaniam et al. further compared the potency of EF24 to curcumin in gastrointestinal cancer cells and demonstrated that EF24 was more potent than curcumin. For example, $1 \mu \mathrm{mol} / \mathrm{L}$ of EF24 significantly suppressed proliferation and colony formation of the colon and gastric cancer cell lines while at the same dose of curcumin had no effect (29). Consistently, EF24 exhibited IC $_{50}$ values 10 to 20 times lower than that of curcumin in multiple cancer cell lines, including lung, ovarian, cervical, breast, prostate cancer cells and cholangiocarcinoma cells (21, 22, 28, 40, 48). Similarly, in human osteogenic sarcoma cells (Saos2), EF24 was 3-fold more potent than curcumin (31). This evidence collectively suggests that EF24 displays much more potent anticancer activity than its parent compound in vitro. Although EF24 shared many anti-cancer mechanisms with its parent compound curcumin, such as inhibiting NF- $\mathrm{B}$ and HIF- $1 \alpha$, it exerts its effects in different ways, for example, in how it regulates HIF$1 \alpha$ activity (described above). In addition, curcumin efficiently inhibited proteasome activity. By contrast, EF24 was 20-fold less active than curcumin for proteasome inhibition (45). Likewise, 
curcumin can regulate the STAT3, while EF24 has no effect on STAT activation (64).

The in vivo activity of a compound relies on the bioavailability of the compound at the site of the tumor. Dietary curcumin is poorly absorbed through the intestinal tract, therefore curcumin does not have a therapeutic effect at low doses (29). By contrast, EF-24 has higher oral bioavailability (60\%) in mice (66), explaining to some extent the improved in vivo activity of EF24 compared to curcumin.

In addition to the improvement of anti-cancer activity, EF24 shows low toxicity to normal cells. EF24 has been shown to induce apoptosis in cancer cells and inhibit the growth of human breast tumors in a mouse xenograft model but showed low toxicity (18). Subramaniam et al. reported that EF24 inhibited intestinal cancer cell proliferation, but did not affect the proliferation of normal mouse embryonic fibroblasts cells, suggesting that EF24 is not toxic to normal cells (29). Similarly, EF24 inhibits tumor growth in human cholangiocarcinoma while displaying low toxicity levels. As a sensitizer, co-treatment of EF24 and rapamycin selectively enhances the cytotoxicity in gastric cancer cells but not in normal cells (60). Above all, multiple molecular targets, wide-spectrum potency, enhanced bioavailability as well as low toxicity to normal cells confer EF24 a series of advantages in clinical applications.

\section{Anti-inflammation Activity}

Inflammation serves as a common mechanism of various diseases including cancer (67), cardiovascular and neurodegenerative diseases $(68,69)$, diabetes $(70)$, and certain neuropsychiatric disorders (71). The NF-кB pathway has been identified to mediate inflammation and therefore is considered as a critical target for development and discovery of drugs for these diseases $(72,73)$. Curcumin has been discovered as a blocker of NF- $\kappa$ B $(74,75)$. As the curcumin analog, EF24 was shown to inhibit LPS-induced pro-inflammatory cytokine mRNA expression and impair LPS-induced NF- $\kappa$ B nuclear translocation (23). Vilekar et al. reported that EF24 can reduce the expression of LPSinduced MHC class II, CD80 and CD86 molecules, as well as reduce NF-kB activity and TNF- $\alpha$ secretion (24). Similarly, EF24 was shown to suppress the LPS-induced TLR4 and IL1R1 expression in dendritic cells (25), which initiate proinflammatory signaling upon ligand binding.

EF24 was also shown to reduce the expression of aquaporin-1, a gene that may be involved in the regulation of immune response in sepsis (76). Stimulation of polymorphonuclear granulocytes by LPS led to increased expression of aquaporin-1 in vitro, which could be abrogated by EF-24. Tissue inflammation led by hemorrhage and aggravated by reperfusion often causes irreversible organ damage. Given the significant inhibitory effect on NF- $\mathrm{B}$, EF24 may play a positive role in reducing the hemorrhage-induced inflammation and symptoms. Yadav et al. revealed that EF24 can prevent the inflammatory status in rats subjected to $50 \%$ hemorrhage, preserve the pulmonary histology, and improve the survival of hemorrhaged rats $(77,78)$. These effects were associated with the inhibition of NF- $\mathrm{B}$ and IL-6R signaling, suggesting EF24 as a promising protective agent in hemorrhage-induced inflammation. The same group found that
EF24 treatment suppressed pro-inflammatory signaling in liver tissue and improved liver functional markers in hemorrhagic shock (79). They also evaluated the effect of EF24 on intestinal barrier dysfunction in hypovolemic shock, and showed EF24 to attenuate hypovolemic gut pathology and protect barrier function by restoring the status of tight junction proteins (80). Because most chronic diseases are mediated through dysregulated inflammation, EF24 has potential use in the prevention of these diseases.

\section{Antibacterial Activity}

Curcumin is well known for its antimicrobial properties, which has been summarized (81). However, as mentioned above, it has very poor bioavailability due to poor absorption in the intestinal tract and in vivo metabolism by the noncytochrome P450 pathway. EF24 and its derived compounds are of considerable interest because of enhanced bioavailability and potency compared to that of curcumin (described above). In 2013, Vilekar et al. evaluated the antibacterial activity of EF24 and revealed it to suppress bacterial growth without affecting the bacterial uptake or localization in the dendritic cells (26). Even though the antibacterial potency of EF24 is much lower than the traditionally used antibiotics, it can potentially be applied as adjunct or chemopreventive agents in critical scenarios. With an aim of investigating cellular and molecular targets, Cocorocchio et al. employed Dictyostelium discoideum mutants and successfully identified the protein phosphatase 2A regulatory subunit PsrA and the presenilin 1 ortholog PsenB that were partially involved in the effect of curcumin and EF24 (82). Recently, Ramayanti et al. investigated the potential of curcumin and its analogs to trigger the Epstein-Barr virus (EBV) lytic cycle in nasopharyngeal (NPC) and gastric carcinoma cells. They found that EF24 showed high lytic inducing activity and enhanced the cytolytic virus activation (83). EF24 therefore may serve as a good adjuvant in cytolytic virus activation treatment.

\section{Neuroprotective Activity}

Reports on the neuroprotective role of EF24 are very limited. One is related to the nitrosative stress that is causal in a select sporadic variant of Parkinson's (PD) and Alzheimer's (AD) diseases. Increased nitric oxide (NO) can disrupt the redox activity of protein-disulfide isomerase, a key chaperone in the endoplasmic reticulum by $\mathrm{S}$-nitroso modification of its redox-active cysteines $(84,85)$. Curcumin has been demonstrated to scavenge nitric oxide (NO) species from model NOx donors (86). Similarly, EF24 exerts neuroprotective effects by ameliorating nitrosative stress-linked damage to protein-disulfide isomerase (PDI) and the associated onset of PD and AD (87).

\section{Progress on Improving Bioactivity and Bioavailability of EF24 New Derivatives Improved Bioactivity of EF24}

To further improve the anti-cancer activity, some groups have moved forward to design and synthesize new analogs of EF24. In 2012, Lagisetty et al. synthesized a hydrazinonicotinic acid conjugate using an amine derivative of EF24. The derivative has improved aqueous solubility compared to EF24, and showed 
significant anti-tumor effects (88). Wu et al. synthesized and purified 20 EF24 analogs, from which they identified one to have greater activity than EF24, showing potent anti-migration and anti-proliferative activity against A549 cells (89). Xie et al. designed and synthesized four series of EF24 analogs, from which they found one displaying excellent inhibition of both IKK $\beta$ activity and pancreatic cancer (PC) development and progression (90). A group from Germany synthesized 14 EF24 analogs and revealed that they have promising anti-proliferative activity against eight cancer cell lines with low $\mathrm{IC}_{50}$ values, and showed superior anti-angiogenic and vascular-disruptive effects (91). Last year, a research group from China synthesized a series of EF24 analogs and identified one to have much greater inhibitory activity against IKK $\beta$ and to induce apoptosis and cell cycle arrest in multiple cancer cell lines (92). Recently, a series of EF24 analogs were synthesized and screened, resulting in one with good potency and selectivity in killing cancer cells (93).

\section{New Drug Delivery Systems (DDS) to Improve the Bioavailability of EF24}

Improving the bioavailability of chemotherapy drugs can greatly increase the therapeutic effect while reducing the side effects. To achieve this aim, specific drug delivery systems (DDS) have been investigated. For example, scientists observed that the tissue factor is aberrantly and abundantly expressed in many cancer cells $(94,95)$, and based on this expression, the group that first designed and synthesize EF24 later proposed a new drug delivery system that associated with tissue factor on the surface of cancer cells, releasing the cytotoxic agent into the cytoplasm. This system displayed a greater effect than EF24 alone in human breast and melanoma cell lines (96). Later, it was reported that the conjugation of EF24 with coagulation factor VIIa induced apoptosis in tumor cells and significantly reduced tumor size in human breast cancer xenografts in athymic nude mice. The targeted drug delivery system has the potential to enhance therapeutic efficacy, while reducing toxic side effects (97). Although EF24 has shown promising in vitro therapeutic efficacy in various human cancer cells, increasing water solubility and systemic bioavailability will be beneficial for its clinical applications. Agashe et al. designed EF24-liposomes and showed their anti-proliferative activity to be superior to that of EF24 alone (98). Bisht et al. designed nano-encapsulation of EF24 into pegylated liposomes (Lipo-EF24), evaluated the particles in pancreatic cancer models, and observed good therapeutic efficacy and favorable toxicity profile (99), which provide evidence for development of future combinatorial therapeutic regimens against pancreatic cancer.

\section{Conclusions and Perspectives}

This review gives a brief summary of the biological and pharmacological activities of EF24, a novel analog of curcumin (Figure 2). Enhanced bioavailability and potency makes it promising as a therapeutic compound alone or combination use with other agents. EF24 has been found to suppress tumor growth by inducing cell cycle arrest or apoptosis in many cancer types. It also shows good anti-inflammatory and anti-bacterial activity. The main mechanisms of action for EF24 include inhibition of the NF- $\kappa$ B pathway and HIF- $1 \alpha$ protein and regulation of the

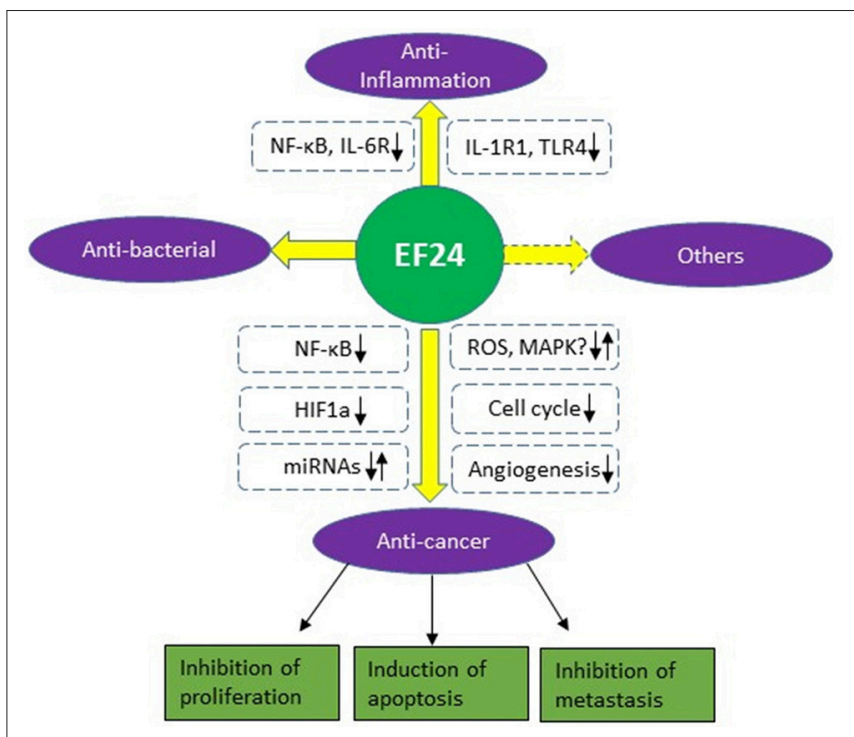

FIGURE 2 | Biological activities and mechanisms of EF24.

MAPK pathway and ROS production. The latter two may be cancer/cell type-dependent and need to be confirmed in future studies.

Natural products usually have biological molecular targets, which confers them multiple bio-activities. Exploring and understanding the targets will provide insights into the mechanisms of action of a natural product and help to improve its efficiency and lower side effects in clinical applications. Based on the known activities of curcumin, we can expect that EF24 may have additional unexplored bioactivities and molecular targets. For example, like some triterpenoid compounds (100, 101), curcumin plays an important role in regulating energy metabolism (102), while application of EF24 in metabolic diseases needs to be determined. In addition, because current therapeutic effects of EF24 are based on cell culture and animal studies, clinical trials are needed to fully verify its therapeutic potential. It is promising that we bring this natural product to the forefront of therapeutic agents for the treatment of human diseases.

\section{AUTHOR CONTRIBUTIONS}

YH: Manuscript writing and figure preparation; WL, GH, HS, and QK: Literature search and manuscript editing.

\section{ACKNOWLEDGMENTS}

This work was supported by grants from National Natural Science Foundation of China (81671404, 81500670), Yunnan Applied Basic Research Project (2017FA038), Scientific Research Foundation of Yunnan Provincial Department of Education (2017YJS075) and the Youth Innovation Promotion Association of Chinese Academy of Sciences (to YH). We thank Dr. Harneet Arora from University of Florida for proofreading and editing the manuscript. 


\section{REFERENCES}

1. Molinski TF, Dalisay DS, Lievens SL, Saludes JP. Drug development from marine natural products. Nat Rev Drug Discov. (2009) 8:69-85. doi: $10.1038 / \mathrm{nrd} 2487$

2. Newman DJ, Cragg GM. Natural products as sources of new drugs from 1981 to 2014. J Nat Prod. (2016) 79:629-61. doi: 10.1021/acs.jnatprod.5b01055

3. Harvey AL. Natural products in drug discovery. Drug Discov Today (2008) 13:894-901. doi: 10.1016/j.drudis.2008.07.004

4. Ruby AJ, Kuttan G, Babu KD, Rajasekharan KN, Kuttan R. Anti-tumour and antioxidant activity of natural curcuminoids. Cancer Lett. (1995) 94:79-83. doi: 10.1016/0304-3835(95)03827-J

5. Sharma OP. Antioxidant activity of curcumin and related compounds. Biochem Pharmacol. (1976) 25:1811-2. doi: 10.1016/0006-2952(76) 90421-4

6. Srimal RC, Dhawan BN. Pharmacology of diferuloyl methane (curcumin), a non-steroidal anti-inflammatory agent. J Pharm Pharmacol. (1973) 25:44752. doi: 10.1111/j.2042-7158.1973.tb09131.x

7. Mahady GB, Pendland SL, Yun G, Lu ZZ. Turmeric (Curcuma longa) and curcumin inhibit the growth of Helicobacter pylori, a group 1 carcinogen. Anticancer Res. (2002) 22:4179-81.

8. Reddy RC, Vatsala PG, Keshamouni VG, Padmanaban G, Rangarajan PN. Curcumin for malaria therapy. Biochem Biophys Res Commun. (2005) 326:472-4. doi: 10.1016/j.bbrc.2004.11.051

9. Jordan WC, Drew CR. Curcumin - a natural herb with anti-HIV activity. J Natl Med Assoc. (1996) 88:333.

10. Kim M, Choi G, Lee H. Fungicidal property of Curcuma longa L. rhizomederived curcumin against phytopathogenic fungi in a greenhouse. J Agric Food Chem. (2003) 51:1578-81. doi: 10.1021/jf0210369

11. Kuttan R, Bhanumathy P, Nirmala K, George MC. Potential anticancer activity of turmeric (Curcuma longa). Cancer Lett. (1985) 29:197-202. doi: 10.1016/0304-3835(85)90159-4

12. Shoba G, Joy D, Joseph T, Majeed M, Rajendran R, Srinivas P. Influence of piperine on the pharmacokinetics of curcumin in animals and human volunteers. Planta Med. (1998) 64:353-6. doi: 10.1055/s-2006957450

13. Anand P, Thomas SG, Kunnumakkara AB, Sundaram C, Harikumar KB, Sung B, et al. Biological activities of curcumin and its analogues (Congeners) made by man and mother nature. Biochem Pharmacol. (2008) 76:1590-611. doi: 10.1016/j.bcp.2008.08.008

14. Hatcher H, Planalp R, Cho J, Tortia FM, Torti SV. Curcumin: from ancient medicine to current clinical trials. Cell Mol Life Sci. (2008) 65:1631-52. doi: 10.1007/s00018-008-7452-4

15. Maheshwari RK, Singh AK, Gaddipati J, Srimal RC. Multiple biological activities of curcumin: a short review. Life Sci. (2006) 78:2081-7. doi: 10.1016/j.lfs.2005.12.007

16. Aggarwal BB, Harikumar KB. Potential therapeutic effects of curcumin, the anti-inflammatory agent, against neurodegenerative, cardiovascular, pulmonary, metabolic, autoimmune and neoplastic diseases. Int J Biochem Cell Biol. (2009) 41:40-59. doi: 10.1016/j.biocel.2008.06.010

17. Gupta SC, Patchva S, Aggarwal BB. Therapeutic roles of curcumin: lessons learned from clinical trials. Aaps J. (2013) 15:195-218. doi: 10.1208/s12248-012-9432-8

18. Adams BK, Ferstl EM, Davis MC, Herold M, Kurtkaya S, Camalier RF, et al. Synthesis and biological evaluation of novel curcumin analogs as anticancer and anti-angiogenesis agents. Bioorg Med Chem. (2004) 12:3871-83. doi: 10.1016/j.bmc.2004.05.006

19. Adams BK, Cai J, Armstrong J, Herold M, Lu YJ, Sun A, et al. EF24, a novel synthetic curcumin analog, induces apoptosis in cancer cells via a redox-dependent mechanism. Anticancer Drugs (2005) 16:263-75. doi: 10.1097/00001813-200503000-00005

20. Skoupa N, Dolezel P, Ruzickova E, Mlejnek P. Apoptosis induced by the curcumin analogue EF-24 is neither mediated by oxidative stress-related mechanisms nor affected by expression of main drug transporters ABCB1 and ABCG2 in human leukemia cells. Int J Mol Sci. (2017) 18:2289. doi: $10.3390 /$ ijms 18112289

21. Kasinski AL, Du Y, Thomas SL, Zhao J, Sun S-Y, Khuri FR, et al. Inhibition of IкB kinase-nuclear factor- $\kappa \mathrm{B}$ signaling pathway by 3, 5-bis (2-flurobenzylidene) piperidin-4-one (EF24), a novel monoketone analog of curcumin. Mol Pharmacol. (2008) 74:654-61. doi: 10.1124/mol.108. 046201

22. Thomas SL, Zhong D, Zhou W, Malik S, Liotta D, Snyder JP, et al. EF24, a novel curcumin analog, disrupts the microtubule cytoskeleton and inhibits HIF-1. Cell Cycle (2008) 7:2409-17. doi: 10.4161/cc.6410

23. Olivera A, Moore TW, Hu F, Brown AP, Sun A, Liotta DC, et al. Inhibition of the NF-кB signaling pathway by the curcumin analog, 3, 5-Bis (2-pyridinylmethylidene)-4-piperidone (EF31): anti-inflammatory and anti-cancer properties. Int Immunopharmacol. (2012) 12:368-77. doi: 10.1016/j.intimp.2011.12.009

24. Vilekar P, Awasthi S, Natarajan A, Anant S, Awasthi V. EF24 suppresses maturation and inflammatory response in dendritic cells. Int Immunol. (2012) 24:455-64. doi: 10.1093/intimm/dxr121

25. Vilekar P, Rao G, Awasthi S, Awasthi V. Diphenyldifluoroketone EF24 suppresses pro-inflammatory interleukin-1 receptor 1 and toll-like receptor 4 in lipopolysaccharide-stimulated dendritic cells. J Inflamm. (2015) 12:55. doi: 10.1186/s12950-015-0096-x

26. Vilekar P, King C, Lagisetty P, Awasthi V, Awasthi S. Antibacterial activity of synthetic curcumin derivatives: 3, 5-bis (benzylidene)-4piperidone (EF24) and EF24-dimer linked via diethylenetriaminepentacetic acid (EF 2 DTPA). Appl Biochem Biotechnol. (2014) 172:3363-73. doi: 10.1007/s12010-014-0741-5

27. Selvendiran K, Tong L, Vishwanath S, Bratasz A, Trigg NJ, Kutala VK, et al. EF24 induces G2/M arrest and apoptosis in cisplatin-resistant human ovarian cancer cells by increasing PTEN expression. J Biol Chem. (2007) 282:28609-18. doi: 10.1074/jbc.M703796200

28. Tan X, Sidell N, Mancini A, Huang R-P, Wang S, Horowitz IR, et al. Multiple anticancer activities of EF24, a novel curcumin analog, on human ovarian carcinoma cells. Reprod Sci. (2010) 17:931-40. doi: $10.1177 / 1933719110374239$

29. Subramaniam D, May R, Sureban SM, Lee KB, George R, Kuppusamy $\mathrm{P}$, et al. Diphenyl difluoroketone: a curcumin derivative with potent in vivo anticancer activity. Cancer Res. (2008) 68:1962-9. doi: 10.1158/0008-5472.CAN-07-6011

30. Bakalova R, Zhelev Z, Shibata S, Nikolova B, Aoki I, Higashi $\mathrm{T}$. Impressive suppression of colon cancer growth by triple combination SN38/EF24/melatonin: "oncogenic" versus "oncosuppressive” reactive oxygen species. Anticancer Res. (2017) 37:5449-58. doi: 10.21873/anticanres.11973

31. Yang S-J, Lee SA, Park M-G, Kim J-S, Yu S-K, Kim CS, et al. Induction of apoptosis by diphenyldifluoroketone in osteogenic sarcoma cells is associated with activation of caspases. Oncol Rep. (2014) 31:2286-92. doi: 10.3892/or.2014.3066

32. Onen HI, Yilmaz A, Alp E, Celik A, Demiroz SM, Konac E, et al. EF24 and RAD001 potentiates the anticancer effect of platinum-based agents in human malignant pleural mesothelioma (MSTO-211H) cells and protects nonmalignant mesothelial (MET-5A) cells. Hum Exp Toxicol. (2015) 34:11726. doi: 10.1177/0960327114542965

33. Bertazza L, Sensi F, Cavedon E, Watutantrige-Fernando S, Censi S, Manso J, et al. EF24 (a curcumin analog) and ZSTK474 emphasize the effect of cabozantinib in medullary thyroid cancer. Endocrinology (2018) 159:234860. doi: 10.1210/en.2018-00124

34. Saglam ASY, Yilmaz A, Onen HI, Alp E, Kayhan H, Ekmekci A. HDAC inhibitors, MS-275 and salermide, potentiates the anticancer effect of EF24 in human pancreatic cancer cells. EXCLI J. (2016) 15:246-55. doi: 10.17179/excli2016-186

35. Santiago-Vázquez Y, Das U, Varela-Ramirez A, Baca ST, Ayala-Marin Y, Lema C, et al. Tumor-selective cytotoxicity of a novel pentadiene analogue on human leukemia/lymphoma cells. Clin Cancer Drugs (2016) 3:138-46. doi: $10.2174 / 2212697 \times 03666160830165250$

36. Lenardo MJ, Baltimore D. NF- $\mathrm{B}$ : a pleiotropic mediator of inducible and tissue-specific gene control. Cell (1989) 58:227-9. doi: 10.1016/0092-8674(89)90833-7

37. Neri A, Chang C-C, Lombardi L, Salina M, Corradini P, Maiolo AT, et al. B cell lymphoma-associated chromosomal translocation involves candidate oncogene lyt-10, homologous to NF-кB p50. Cell (1991) 67:1075-87. doi: 10.1016/0092-8674(91)90285-7 
38. Higgins KA, Perez JR, Coleman TA, Dorshkind K, McComas WA, Sarmiento $\mathrm{UM}$, et al. Antisense inhibition of the p65 subunit of NF-kappa B blocks tumorigenicity and causes tumor regression. Proc Natl Acad Sci. (1993) 90:9901-5. doi: 10.1073/pnas.90.21.9901

39. Liang Y, Yin D, Hou L, Zheng T, Wang J, Meng X, et al. Diphenyl difluoroketone: a potent chemotherapy candidate for human hepatocellular carcinoma. PLoS ONE (2011) 6:e23908. doi: 10.1371/journal.pone.00 23908

40. Yin D, Liang Y, Zheng T, Song R, Wang J, Sun B, et al. EF24 inhibits tumor growth and metastasis via suppressing NF-kappaB dependent pathways in human cholangiocarcinoma. Sci Rep. (2016) 6:32167. doi: 10.1038/srep32167

41. Liu H, Liang Y, Wang L, Tian L, Song R, Han T, et al. In vivo and in vitro suppression of hepatocellular carcinoma by EF24, a curcumin analog. PLoS ONE (2012) 7:e48075. doi: 10.1371/journal.pone.0048075

42. Zhao R, Tin L, Zhang Y, Wu Y, Jin Y, Jin X, et al. EF24 suppresses invasion and migration of hepatocellular carcinoma cells in vitro via inhibiting the phosphorylation of Src. BioMed Res Int. (2016) 2016:8569684. doi: 10.1155/2016/8569684.

43. Aravindan S, Natarajan M, Herman TS, Awasthi V, Aravindan N. Molecular basis of 'hypoxic'breast cancer cell radio-sensitization: phytochemicals converge on radiation induced Rel signaling. Radiat Oncol. (2013) 8:46. doi: $10.1186 / 1748-717 x-8-46$

44. Aravindan S, Natarajan M, Awasthi V, Herman TS, Aravindan N. Novel synthetic monoketone transmute radiation-triggered NFKB-dependent TNF $\alpha$ cross-signaling feedback maintained NFKB and favors neuroblastoma regression. PLoS ONE (2013) 8:e72464. doi: 10.1371/journal.pone. 0072464

45. Landais I, Hiddingh S, McCarroll M, Yang C, Sun A, Turker MS, et al. Monoketone analogs of curcumin, a new class of Fanconi anemia pathway inhibitors. Mol Cancer (2009) 8:133. doi: 10.1186/1476-4598-8-133

46. Tuyt LM, Dokter WH, Birkenkamp K, Koopmans SB, Lummen C, Kruijer $\mathrm{W}$, et al. Extracellular-regulated kinase 1/2, Jun N-terminal kinase, and c-Jun are involved in NF- $\kappa \mathrm{B}$-dependent IL-6 expression in human monocytes. $J$ Immunol. (1999) 162:4893-902.

47. Berghe WV, Plaisance S, Boone E, De Bosscher K, Schmitz ML, Fiers W, et al. p38 and extracellular signal-regulated kinase mitogen-activated protein kinase pathways are required for nuclear factor- $\mathrm{B}$ p65 transactivation mediated by tumor necrosis factor. J Biol Chem. (1998) 273:3285-90. doi: $10.1074 /$ jbc. 273.6 .3285

48. Thomas SL, Zhao J, Li Z, Lou B, Du Y, Purcell J, et al. Activation of the p38 pathway by a novel monoketone curcumin analog, EF24, suggests a potential combination strategy. Biochem Pharmacol. (2010) 80:1309-16. doi: 10.1016/j.bcp.2010.06.048

49. Lin C, Tu C, Ma Y, Ye P, Shao X, Yang Z, et al. Curcumin analog EF24 induces apoptosis and downregulates the mitogen activated protein kinase/extracellular signal-regulated signaling pathway in oral squamous cell carcinoma. Mol Med Rep. (2017) 16:4927-33. doi: 10.3892/mmr.2017. 7189

50. Liang Y, Zheng T, Song R, Wang J, Yin D, Wang L, et al. Hypoxia-mediated sorafenib resistance can be overcome by EF24 through Von Hippel-Lindau tumor suppressor-dependent HIF-1 $\alpha$ inhibition in hepatocellular carcinoma. Hepatology (2013) 57:1847-57. doi: 10.1002/hep.26224

51. Bae M-K, Kim S-H, Jeong J-W, Lee YM, Kim H-S, Kim S-R, et al. Curcumin inhibits hypoxia-induced angiogenesis via down-regulation of HIF-1. Oncol Rep. (2006) 15:1557-62. doi: 10.3892/or.15.6.1557

52. Airley RE, Mobasheri A. Hypoxic regulation of glucose transport, anaerobic metabolism and angiogenesis in cancer: novel pathways and targets for anticancer therapeutics. Chemotherapy (2007) 53:233-56. doi: 10.1159/000104457

53. Vander Heiden MG, Cantley LC, Thompson CB. Understanding the Warburg effect: the metabolic requirements of cell proliferation. Science (2009) 324:1029-33. doi: 10.1126/science.1160809

54. Zhang D, Wang Y, Dong L, Huang Y, Yuan J, Ben W, et al. Therapeutic role of EF 24 targeting glucose transporter 1-mediated metabolism and metastasis in ovarian cancer cells. Cancer Sci. (2013) 104:1690-6. doi: 10.1111/cas.12293

55. Ambrosone CB. Oxidants and antioxidants in breast cancer. Antioxid Redox Signal. (2000) 2:903-17. doi: 10.1089/ars.2000.2.4-903
56. Storz P. Reactive oxygen species in tumor progression. Front Biosci. (2005) 10:1881-96. doi: 10.2741/1667

57. Emerit I. Reactive oxygen species, chromosome mutation, and cancer: possible role of clastogenic factors in carcinogenesis. Free Radic Biol Med. (1994) 16:99-109. doi: 10.1016/0891-5849(94)90246-1

58. Roy D, Kabiraj P, Pal R. EF24 prevents rotenone-induced estrogenic status alteration in breast cancer. Cell Biol Int. (2014) 38:511-9. doi: 10.1002/cbin.10224

59. Zou P, Xia Y, Chen W, Chen X, Ying S, Feng Z, et al. EF24 induces ROS-mediated apoptosis via targeting thioredoxin reductase 1 in gastric cancer cells. Oncotarget (2016) 7:18050-64. doi: 10.18632/oncotarget. 7633

60. Chen W, Zou P, Zhao Z, Chen X, Fan X, Vinothkumar R, et al. Synergistic antitumor activity of rapamycin and EF24 via increasing ROS for the treatment of gastric cancer. Redox Biol. (2016) 10:78-89. doi: 10.1016/j.redox.2016.09.006

61. Chen X, Dai X, Zou P, Chen W, Rajamanickam V, Feng C, et al. Curcuminoid EF24 enhances the anti-tumour activity of Akt inhibitor MK-2206 through ROS-mediated endoplasmic reticulum stress and mitochondrial dysfunction in gastric cancer. Br J Pharmacol. (2017) 174:1131-46. doi: 10.1111/bph. 13765

62. He G, Feng C, Vinothkumar R, Chen W, Dai X, Chen X, et al. Curcumin analog EF24 induces apoptosis via ROS-dependent mitochondrial dysfunction in human colorectal cancer cells. Cancer Chemother Pharmacol. (2016) 78:1151-61. doi: 10.1007/s00280-016-3172-x

63. Calin GA, Croce CM. MicroRNA signatures in human cancers. Nat Rev Cancer (2006) 6:857. doi: 10.1038/nrc1997

64. Yang $\mathrm{CH}$, Yue J, Sims $\mathrm{M}$, Pfeffer LM. The curcumin analog EF24 targets NF-кB and miRNA-21, and has potent anticancer activity in vitro and in vivo. PLoS ONE (2013) 8:e71130. doi: 10.1371/journal.pone. 0071130

65. Zhang P, Bai H, Liu G, Wang H, Chen F, Zhang B, et al. MicroRNA33b, upregulated by EF24, a curcumin analog, suppresses the epithelial-to-mesenchymal transition (EMT) and migratory potential of melanoma cells by targeting HMGA2. Toxicol Lett. (2015) 234:151-61. doi: 10.1016/j.toxlet.2015.02.018

66. Reid JM, Buhrow SA, Gilbert JA, Jia L, Shoji M, Snyder JP, et al. Mouse pharmacokinetics and metabolism of the curcumin analog, 4-piperidinone,3,5-bis[(2-fluorophenyl)methylene]-acetate(3E,5E) (EF24; NSC 716993). Cancer Chemother Pharmacol. (2014) 73:1137-46. doi: $10.1007 /$ s00280-014-2447-3

67. Coussens LM, Werb Z. Inflammation and cancer. Nature (2002) 420:860. doi: 10.1038/nature01322

68. Libby P. Inflammation and cardiovascular disease mechanisms. Am J Clin Nutr. (2006) 83:456S-60S. doi: 10.1093/ajcn/83.2.456S

69. Amor S, Puentes F, Baker D, Van Der Valk P. Inflammation in neurodegenerative diseases. Immunology (2010) 129:154-69. doi: 10.1111/j.1365-2567.2009.03225.x

70. Wellen KE, Hotamisligil GS. Inflammation, stress, and diabetes. J Clin Invest. (2005) 115:1111-9. doi: 10.1172/JCI25102

71. Miller AH, Maletic V, Raison CL. Inflammation and its discontents: the role of cytokines in the pathophysiology of major depression. Biol Psychiatr. (2009) 65:732-41. doi: 10.1016/j.biopsych.2008.11.029

72. Tak PP, Firestein GS. NF-кB: a key role in inflammatory diseases. J Clin Invest. (2001) 107:7-11. doi: 10.1172/JCI11830

73. Aggarwall BB. Nuclear factor-kappaB: the enemy within cancer. Cancer Cell (2004) 6:203-8. doi: 10.1016/j.ccr.2004.09.003

74. Sikora E, Scapagnini G, Barbagallo M. Curcumin, inflammation, ageing and age-related diseases. Immun Ageing (2010) 7:1. doi: 10.1186/17424933-7-1

75. He Y, Yue Y, Zheng X, Zhang K, Chen S, Du Z. Curcumin, inflammation, and chronic diseases: how are they linked? Molecules (2015) 20:9183-213. doi: 10.3390/molecules20059183

76. Vassiliou AG, Maniatis NA, Orfanos SE, Mastora Z, Jahaj E, Paparountas $\mathrm{T}$, et al. Induced expression and functional effects of aquaporin-1 in human leukocytes in sepsis. Crit Care (2013) 17:R199. doi: 10.1186/ cc12893 
77. Yadav VR, Sahoo K, Roberts PR, Awasthi V. Pharmacologic suppression of inflammation by a diphenyldifluoroketone, EF24, in a rat model of fixed-volume hemorrhage improves survival. J Pharmacol Exp Ther. (2013) 347:346-56. doi: 10.1124/jpet.113.208009

78. Yadav VR, Vilekar P, Awasthi S, Awasthi V. Hemorrhage-induced interleukin-1 receptor pathway in lung is suppressed by 3, 5-bis (2fluorobenzylidene)-4-piperidone in a rat model of hypovolemic shock. Artif Organs (2014) 38:675-83. doi: 10.1111/aor.12305

79. Yadav VR, Hussain A, Xie J, Kosanke S, Awasthi V. The salutary effects of diphenyldifluoroketone EF24 in liver of a rat hemorrhagic shock model. Scand J Trauma Resusc Emerg Med. (2015) 23:8. doi: 10.1186/s13049-015-0098-y

80. Yadav VR, Hussain A, Sahoo K, Awasthi V. Remediation of hemorrhagic shock-induced intestinal barrier dysfunction by treatment with diphenyldihaloketones EF24 and CLEFMA. J Pharmacol Exp Ther. (2014) 351:413-22. doi: 10.1124/jpet.114.217331

81. Zorofchian Moghadamtousi S, Abdul Kadir H, Hassandarvish P, Tajik H, Abubakar S, Zandi K. A review on antibacterial, antiviral, and antifungal activity of curcumin. BioMed Res Int. (2014) 2014:186864. doi: 10.1155/2014/ 186864

82. Cocorocchio M, Baldwin AJ, Stewart B, Kim L, Harwood AJ, Thompson CR, et al. Curcumin and derivatives function through protein phosphatase $2 \mathrm{~A}$ and presenilin orthologues in Dictyostelium discoideum. Dis Model Mech. (2017) 11:dmm032375. doi: 10.1242/dmm.032375

83. Ramayanti O, Brinkkemper M, Verkuijlen SA, Ritmaleni L, Go ML, Middeldorp JM. Curcuminoids as EBV lytic activators for adjuvant treatment in EBV-positive carcinomas. Cancers (2018) 10:89. doi: $10.3390 /$ cancers 10040089

84. Mattson MP. Nitro-PDI incites toxic waste accumulation. Nat Neurosci. (2006) 9:865. doi: 10.1038/nn0706-865

85. Uehara T, Nakamura T, Yao D, Shi Z-Q, Gu Z, Ma Y, et al. S-nitrosylated protein-disulphide isomerase links protein misfolding to neurodegeneration. Nature (2006) 441:513. doi: 10.1038/nature04782

86. Pal R, Cristan EA, Schnittker K, Narayan M. Rescue of ER oxidoreductase function through polyphenolic phytochemical intervention: implications for subcellular traffic and neurodegenerative disorders. Biochem Biophys Res Commun. (2010) 392:567-71. doi: 10.1016/j.bbrc.2010. 01.071

87. Pal R, Miranda M, Narayan M. Nitrosative stress-induced Parkinsonian Lewy-like aggregates prevented through polyphenolic phytochemical analog intervention. Biochem Biophys Res Commun. (2011) 404:324-9. doi: 10.1016/j.bbrc.2010.11.117

88. Lagisetty $\mathrm{P}$, Subramaniam D, Sahoo K, Anant S, Awasthi V. Anticancer Activity of an Imageable curcuminoid 1-[2-aminoethyl(6-hydrazinopyridine-3-carbamidyl)-3, 5-bis-(2-fluorobenzylidene)4-piperidone (EFAH). Chem Biol Drug Des. (2012) 79:194-201. doi: 10.1111/j.1747-0285.2011.01271.x

89. Wu J, Wu S, Shi L, Zhang S, Ren J, Yao S, et al. Design, synthesis, and evaluation of asymmetric EF24 analogues as potential anticancer agents for lung cancer. Eur J Med Chem. (2017) 125:1321-31. doi: 10.1016/j.ejmech.2016.10.027

90. Xie X, Tu J, You H, Hu B. Design, synthesis, and biological evaluation of novel EF24 and EF31 analogs as potential ІкB kinase $\beta$ inhibitors for the treatment of pancreatic cancer. Drug Des Devel Ther. (2017) 11:1439. doi: 10.2147/DDDT.S133172
91. Schmitt F, Gold M, Begemann G, Andronache I, Biersack B, Schobert R. Fluoro and pentafluorothio analogs of the antitumoral curcuminoid EF24 with superior antiangiogenic and vascular-disruptive effects. Bioorg Med Chem. (2017) 25:4894-903. doi: 10.1016/j.bmc.2017. 07.039

92. Jin R, Chen Q, Yao S, Bai E, Fu W, Wang L, et al. Synthesis and antitumor activity of EF24 analogues as IKK $\beta$ inhibitors. Eur J Med Chem. (2018) 144:218-28. doi: 10.1016/j.ejmech.2017.11.077

93. Chen L, Li Q, Weng B, Wang J, Zhou Y, Cheng D, et al. Design, synthesis, anti-lung cancer activity, and chemosensitization of tumorselective MCACs based on ROS-mediated JNK pathway activation and NF-кB pathway inhibition. Eur J Med Chem. (2018) 151:508-19. doi: 10.1016/j.ejmech.2018.03.051

94. Callander NS, Varki N, Vijaya Rao LM. Immunohistochemical identification of tissue factor in solid tumors. Cancer (1992) 70:1194-201.

95. Contrino J, Hair G, Kreutzer DL, Rickles FR. In situ detection of tissue factor in vascular endothelial cells: correlation with the malignant phenotype of human breast disease. Nat Med. (1996) 2:209. doi: 10.1038/nm0296-209

96. Sun A, Shoji M, Lu YJ, Liotta DC, Snyder JP. Synthesis of EF24- tripeptide chloromethyl ketone: a novel curcumin-related anticancer drug delivery system. J Med Chem. (2006) 49:3153-8. doi: 10.1021/jm051141k

97. Shoji M, Sun A, Kisiel W, Lu YJ, Shim H, McCarey BE, et al. Targeting tissue factor-expressing tumor angiogenesis and tumors with EF24 conjugated to factor VIIa. J Drug Target (2008) 16:185-97. doi: 10.1080/10611860801890093

98. Agashe H, Lagisetty P, Sahoo K, Bourne D, Grady B, Awasthi V. Liposomeencapsulated EF24-HPßCD inclusion complex: a preformulation study and biodistribution in a rat model. J Nanoparticle Res. (2011) 13:2609-23. doi: 10.1007/s11051-010-0154-5

99. Bisht S, Schlesinger M, Rupp A, Schubert R, Nolting J, Wenzel J, et al. A liposomal formulation of the synthetic curcumin analog EF24 (LipoEF24) inhibits pancreatic cancer progression: towards future combination therapies. J Nanobiotechnol. (2016) 14:57. doi: 10.1186/s12951-0160209-6

100. He Y, Li Y, Zhao T, Wang Y, Sun C. Ursolic acid inhibits adipogenesis in 3T3L1 adipocytes through LKB1/AMPK pathway. PLoS ONE (2013) 8:e70135. doi: 10.1371/journal.pone.0070135

101. He Y, Li W, Li Y, Zhang S, Wang Y, Sun C. Ursolic acid increases glucose uptake through the PI3K signaling pathway in adipocytes. PLOS ONE (2014) 9:e110711. doi: 10.1371/journal.pone.0110711

102. Aggarwal BB. Targeting inflammation-induced obesity and metabolic diseases by curcumin and other nutraceuticals. Annu Rev Nutr. (2010) 30:173-99. doi: 10.1146/annurev.nutr.012809.104755

Conflict of Interest Statement: The authors declare that the research was conducted in the absence of any commercial or financial relationships that could be construed as a potential conflict of interest.

Copyright (c) $2018 \mathrm{He}, \mathrm{Li}, \mathrm{Hu}$, Sun and Kong. This is an open-access article distributed under the terms of the Creative Commons Attribution License (CC BY). The use, distribution or reproduction in other forums is permitted, provided the original author(s) and the copyright owner(s) are credited and that the original publication in this journal is cited, in accordance with accepted academic practice. No use, distribution or reproduction is permitted which does not comply with these terms. 